\title{
Recovery trajectories of coral reef fish assemblages within Kenyan marine protected areas
}

\author{
T. R. McClanahan ${ }^{1, *}$, N. A. J. Graham ${ }^{2}$ \\ ${ }^{1}$ Marine Programs, Wildlife Conservation Society, Bronx, New York 10460, USA \\ ${ }^{2}$ School of Marine Science and Technology, University of Newcastle, Newcastle-upon-Tyne NE1 7RU, UK
}

\begin{abstract}
The size, density and biomass of coral reef fish in 4 fully closed marine protected areas (MPAs) with different ages were studied over a 17 yr period. Space-for-time substitution samples were available for a period of $4 \mathrm{yr}$ before, and $36 \mathrm{yr}$ after the closure. Both the height of the size structure graph (which is a value of overall abundance-biomass) and the assemblage biomass graph are convex polynomials with a maximum biomass of $1200 \mathrm{~kg} \mathrm{ha}^{-1}$ at $22 \mathrm{yr}$. This suggests that full recovery of coral reef fish assemblages in terms of abundance-biomass is considerably longer than generally believed. Beyond $25 \mathrm{yr}$, there can be a small loss in biomass, which we suggest is due to reduced net primary production associated with the increased abundance of calcifying algae attributable to intense grazing. Size spectra slopes were variable at all times, changed quickly, and were probably influenced by local environmental conditions, which made concise predictions for equilibrium coral reef size structure rather difficult.
\end{abstract}

KEY WORDS: Biomass $\cdot$ Recovery $\cdot$ Marine protected areas $\cdot$ Calcifying algae $\cdot$ Fish growth $\cdot$ Size spectra

\section{INTRODUCTION}

Fish recovery from fishing has implications for the design of closed areas and determining the equilibrium abundance and structure of exploited species, which can help with conservation and harvesting models and decisions (Russ \& Alcala 2004). A recent metaanalysis of 112 closed areas suggested that the effects of fisheries closures on fisheries target groups are rapid, on the scale of a few years (Halpern \& Warner 2002). There are, however, time-dependent processes in ecosystems that operate and interact on many scales, and theory suggests that only some processes will be rapid (Levin 2000, Allen \& Holling 2002, McClanahan et al. 2002). The few site-specific studies of recovery of harvested fish in coral reefs indicate that full recovery of fish populations may be considerably more than a few years (McClanahan \& Kaunda-Arara 1996, McClanahan 2000, Russ \& Alcala 2004). Until more moderate to long-term time series studies are completed and the scale of various recovery processes are uncovered, the aforementioned predictions for the recovery rates of closed-area management will remain simple and unresolved.

Because many ecological processes vary over considerable timescales and because human influences are widespread, there is a need for concerted efforts to collect data at multiple scales in areas with minimum human influences, in order to establish baselines for understanding human influences (Pauly et al. 1998). This is of particular concern for marine ecosystems, given that marine protected areas (MPAs) are a modern conservation phenomenon (Kelleher et al. 1995), and that most studies of MPAs, apart from meta-analyses (Mosquera et al. 2000, Cote et al. 2001, Halpern 2003), are based on only one or a few closed areas often at one point in time and measured effects are sensitive to the control or reference sites used for comparison of effectiveness (Willis et al. 2003, Sale et al. 2005). There is a need to use methods such as meta-analysis and patching together time series using space-for-time substitutions to create chronose- 
quences with different initial starting points of management in order to test for general patterns that are not site- or timerestricted.

With increasing calls for ecosystem approaches to fisheries management (Link 2002, Browman \& Stergiou 2004, Pikitch et al. 2004), the use of aggregated techniques (such as size-based approaches to analyze assemblage data) are becoming more common (Rochet \& Trenkel 2003). As maximum size is correlated with many other life-history traits, resulting in larger fish being more vulnerable to exploitation (Jennings et al. 1999, Denny et al. 2002) and because larger fish are generally targeted before smaller fish (Pauly et al. 1998), size is proving to be a useful way to assess multispecies fisheries (Bianchi et al. 2000, Dulvy et al. 2004, Graham et al. 2005). Increasing evidence of species-level (Watson and Ormond 1994, Graham et al. 2003) and aggregated size-based (Dulvy et al. 2004) indirect interactions within coral reef fish assemblages further suggest that recovery trajectories in these ecosystems should be assessed at the assemblage level.

This study examines the size structure and biomass of coral reef fishes in Kenyan coral reefs by examining 4 fully closed MPAs that vary in their time of establishment (from 1968 to 1991) with data that are available from $4 \mathrm{yr}$ prior to and $36 \mathrm{yr}$ after closed-area management (see Table 1). The study sites were examined between 1987 and 2004, and repeatedly sampled so that a $40 \mathrm{yr}$ chronosequence of management can be patched together from this sampling and differences in the starting dates for closed-area management. Here, we focus on the recovery of biomass and size structure of the total fish population as a function of the age of the closedarea protection to determine if there are consistent and general patterns and equilibrium levels for each of these factors.

Table 1. Description of the 4 studied marine protected areas in Kenya including the time since closure from fishing, closed-area size, and 2 important habitat variables (mean $\pm \mathrm{SD})$

\begin{tabular}{|lccccc|}
\hline & \multicolumn{2}{c}{ Closure } & \multicolumn{2}{c|}{ Habitat variables } & Site $\times$ Time \\
& $\begin{array}{c}\text { Date } \\
(\text { year })\end{array}$ & $\begin{array}{c}\text { Size } \\
\left(\mathrm{km}^{2}\right)\end{array}$ & $\begin{array}{c}\text { Hard coral } \\
(\%)\end{array}$ & $\begin{array}{c}\text { Rugosity } \\
\left(\mathrm{m} \mathrm{m}^{-1}\right)\end{array}$ & replication \\
\hline Malindi & 1968 & 6.3 & $25.9 \pm 12.4$ & $1.30 \pm 0.0$ & 29 \\
Watamu & 1972 & 10.0 & $26.6 \pm 13.0$ & $1.31 \pm 0.0$ & 30 \\
Kisite & 1973 & 28.0 & $26.7 \pm 17.3$ & $1.18 \pm 0.1$ & 10 \\
Mombasa & 1991 & 6.0 & $29.8 \pm 12.7$ & $1.31 \pm 0.1$ & 32 \\
\hline
\end{tabular}

\section{MATERIALS AND METHODS}

Study sites. The fully protected study areas lie along a $180 \mathrm{~km}$ stretch of southern Kenya (Fig. 1). They vary in size from around 6 to $28 \mathrm{~km}^{2}$ and were legally gazetted between 1968 and 1988; Malindi and Watamu in 1968, Kisite in 1973, and Mombasa in 1988 (Table 1). The starting dates for management are, however, often somewhat different and not easily determined with accuracy. Since management in Malindi and Watamu was originally focused on Malindi, we gave Malindi a 1968 starting date and Watamu a 1972 starting date. Kisite was regazetted in 1978, and this is often given as the starting date for this park (Sheppard \& Wells 1988), but this 1978 regazettement was to open up a fully closed area to restricted fishing, and we therefore used the original date of 1973. The first author was working in the Mombasa park around the period from gazettement to implementation, and chose 1991 as a starting date for this park, from this date fishermen were excluded. The management practices are consistent between the parks, all of which are being enforced by the Kenyan Wildlife Services. The closure area of $28 \mathrm{~km}^{2}$ given for the 
Kisite MNP over-represents the area in the coral reef, which is closer to $10 \mathrm{~km}^{2}$, and much of the remaining area is sandy bottom (T. R. McClanahan pers. obs.). The Kisite site was sampled for fish twice and benthic cover 5 times during the study period, and therefore the fish data were not used in site-specific analyses but only when compiling chronosequences. All sites are similar shallow leeward or back reef areas $(<2 \mathrm{~m}$ at low tide) that are dominated by living and dead coral that is colonized by various forms of algae (Table 1).

Fish and benthic field sampling. Fish communities were quantified using 2 to 5 replicate $5 \times 100 \mathrm{~m}$ belt transects per site (McClanahan 1994, McClanahan \& Kaunda-Arara 1996). Wet-weight estimates were made by classifying each individual encountered in transects to the family, estimating its length, and placing it into $10 \mathrm{~cm}$ size-class intervals, up to $40 \mathrm{~cm}$ and with no individuals $<3 \mathrm{~cm}$ in length recorded. Data were collected and placed in 11 taxonomic categories and 1 group of 'others' or all other fish (McClanahan 1994). Small and cryptic taxa such as blennies, tobies, and gobies were sampled but probably underestimated (Ackerman \& Bellwood 2004). For the purpose of this study, we pooled all groups and analyzed the pooled data. Wet weights per family were estimated from length-weight correlations established from measurements of the common species in each family taken at local fish landing sites in Kenya (McClanahan \& KaundaArara 1996). This method is not accurate for the small and cryptic species but obtains reasonable estimates of fish wet weights because the larger and more exposed species make up the largest fraction of the total fish weight. The estimate of biomass removes the 3 to $10 \mathrm{~cm}$ size class, which is small, assumed to be under-sampled, and also not a part of the fisheries targets.

Attached benthic communities were described by the line-intercept method using 9 to 27 10-m line transects at each site per year. Cover of benthic biota under the line $>3 \mathrm{~cm}$ in length was classified into 9 gross substratum categories (hard coral, soft coral, algal turf, coralline algae, calcareous algae, fleshy algae, seagrass, sand, and sponge) and their lengths were measured to the nearest centimeter (McClanahan \& Shafir 1990). Cover of the functional groups was calculated as numbers of centimeters per meter of line transect, and in this study we sum the 2 calcifying algal groups (green and red calcareous or coralline algae) and divide by the sum of the turf and frondose algae. This cover ratio gives a measure of the ratio of calcifying and non-calcifying algae, which is expected to be a gross measure of net production on these reefs (Steneck \& Dethier 1994).

Data analyses. Fish data were principally analyzed at the aggregated level using size-spectra analysis. This technique describes the size composition of communities by studying the relationship between abun- dance by body-size class and body size of the aggregated assemblage regardless of taxonomy (Kerr \& Dickie 2001). Individual fish censused were allocated to body-length class groupings from 10 to $>40 \mathrm{~cm}$. Slopes of the size spectra were calculated from linear regressions of $\log _{10}(x+1)$ numbers per size class on the rescaled $\log _{10}$ mid-point of each length class. This centering of the independent variable gives a value for mid-point height as opposed to the intercept, thus removing the correlation between slope and intercept (Daan et al. 2003). Mid-point height is an index of the assemblage abundance-biomass (Trenkel \& Rochet 2003). The significance of both slope and height for each of the 3 most sampled MPAs was tested using linear regression individually, to test the site-level structure of the data, and a second-order polynomial trend was fitted to the height data. The significance of trends in size-class data for the 3 most sampled MPAs, Malindi, Watamu, and Mombasa, was tested separately, with linear regression by each size class for each management area. Aggregated biomass data $(>10 \mathrm{~cm}$ ) for all fish surveyed was also independently analyzed with linear regression for each of the MPAs. Trends in the ratio of calcifying and non-calcifying algae were analyzed as a function of the age of the protected area using a GLM ANCOVA procedure with years of protection as a covariate. However, due to an interaction between years of protection and site, due to not enough overlap in the age of the MPAs, statistics across all parks combined could not be used. We therefore analyzed the 3 most sampled MPAs separately using linear regression and present the data on the same plot as a means to visualize the overall pattern.

\section{RESULTS}

Size-spectra slopes for all size classes were quite variable (ranging from -0.35 to -0.78 ) at all sites and times and were not statistically significant for regressions with time (Malindi $F_{1,10}=2.06$, Watamu $F_{1,10}=$ 0.27, Mombasa $F_{1,11}=1.59$; Fig. 2a). There are often rapid changes from year to year that create high variability and mask any potential trends with time. The size-spectra slope rises in the youngest marine park, Mombasa, however the trend was only statistically significant when examining the density of the different size classes (Fig. 3). In Mombasa, the densities rise over time significantly for the 20 to 30 and 30 to 40 sizeclass intervals. Individual size classes are more stable in Watamu and Malindi, with the exception that the 10 to $20 \mathrm{~cm}$ size class declined over time in Malindi.

The height (or $y$-intercepts) of the size spectra equations and the biomass estimates for all sites and times combined indicate a hump-shaped relationship with 

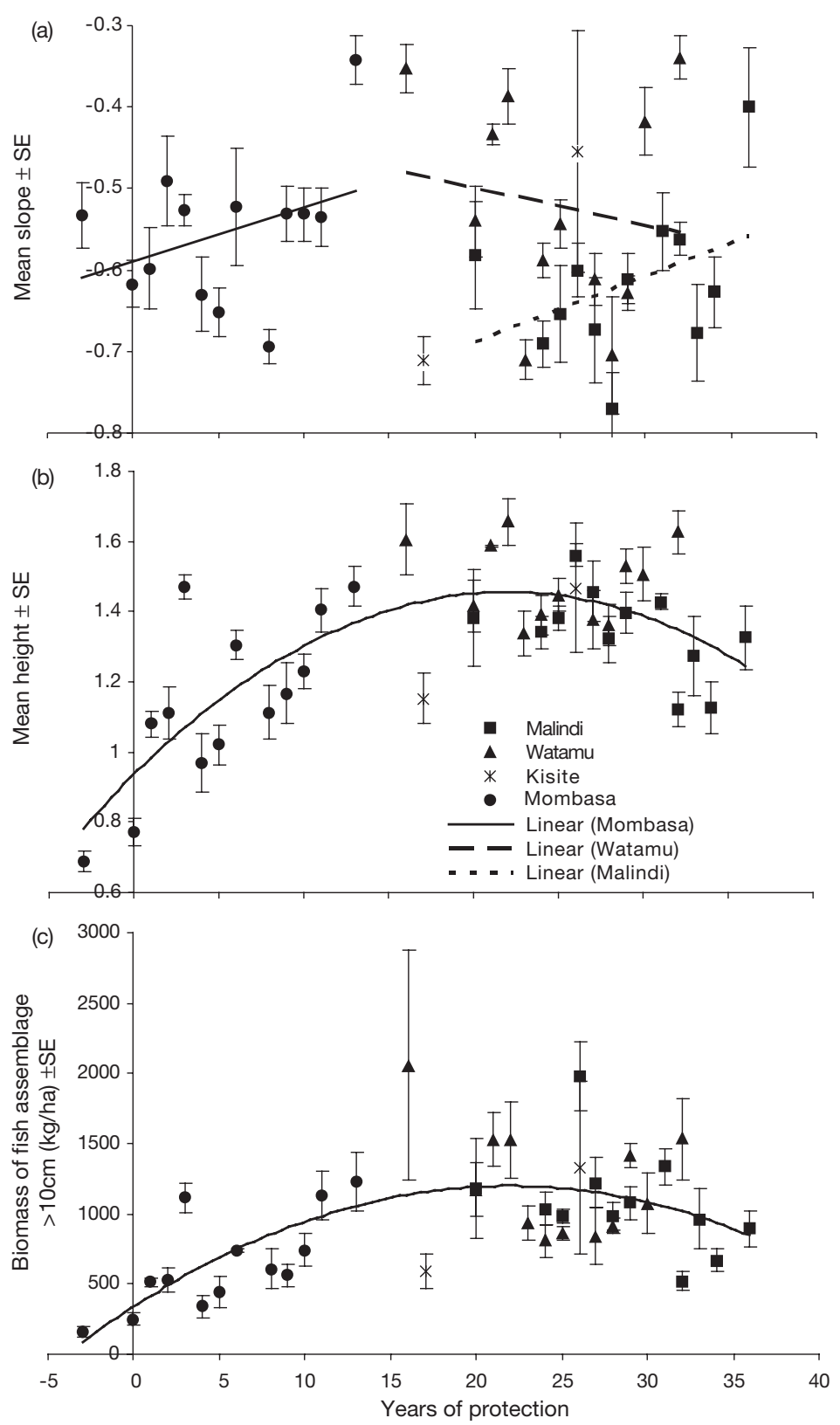

Fig. 2. Scatter plots of the (a) slope and (b) height of the size spectra and (c) estimated biomass of fish $>10 \mathrm{~cm}$ as a function of the age of the protected area. The trend lines fitted to plots (b) and (c) are for visualisation of the data but do not reflect the statistics, which are presented in the 'Results'

time with maximum height and biomass between 21 and 22 yr (Fig. 2b,c). When analyzed for each site separately, the relationship between height and time is, however, only significant for Mombasa $\left(F_{1,11}=12.9, \mathrm{p}<0.01\right)$, and weakly negative for Malindi $\left(F_{1,10}=3.54, \mathrm{p}=0.09\right)$ and no relationship for Watamu $\left(F_{1,10}=0.09\right)$. Similarly, biomass increases significantly for Mombasa $\left(F_{1,11}=11.7\right.$, $\mathrm{p}<0.01)$ but does not change with time for Malindi $\left(F_{1,10}=2.44, \mathrm{p}=0.15\right)$ or Watamu $\left(F_{1,10}=1.88, \mathrm{p}=0.20\right)$.
Benthic cover data suggests a rising trend in the ratio of calcifying to non-calcifying algae as a function of the age of the protected area (Fig. 4). The rise in Mombasa in the first $13 \mathrm{yr}$ of protection increases linearly $\left(F_{1,12}=34.4, \mathrm{p}<0.0001\right)$, but above around $20 \mathrm{yr}$, the data are variable and site dependent (Malindi $F_{1,12}=4.23, \mathrm{p}<0.06$, Watamu $F_{1,12}=3.65$, $\mathrm{p}<0.08$ ) with Malindi having the highest ratio. Nonetheless, an exponential fit to the data for all sites combined is strong $\left(\mathrm{r}^{2}=0.72\right)$.

\section{DISCUSSION}

This study indicates that it takes a considerable time (just over $20 \mathrm{yr}$ ) for coral reef fish to recover their full biomass in Kenya. This finding is similar to the only other moderate-term studies of fish recovery in coral reefs (McClanahan 2000, Russ \& Alcala 2004). Russ \& Alcala (2004) reported that large predatory fish were still recovering after 9 and $18 \mathrm{yr}$ of protection in 2 studied marine parks in the Philippines. By fitting their data to a logistic model of fish population growth, they estimated that the time to full recovery was 15 and $40 \mathrm{yr}$ for the 2 closed areas, which is in the range predicted for the recovery of the red-lined triggerfish, an important keystone predator on Kenyan coral reefs (McClanahan 2000). Consequently, both studies suggest that $>15 \mathrm{yr}$ is required to recover fish biomass, which is considerably longer than the 1 to $3 \mathrm{yr}$ suggested by a meta-analysis of 112 closed areas (Halpern \& Warner 2003). We agree with Russ \& Alcala (2004) that the meta-analysis method does not coincide with the theoretical expectations of these time-dependent processes and is sensitive to differences in the selection of sites and the history and effectiveness of their management. Although Halpern \& Warner (2003) suggest that recovery times in reserves are within a few years, their study indicates that time was not a statistically significant factor, which is biologically unrealistic unless rapid immigration into recently closed areas is the dominant process of recovery. We therefore suggest that there are some systematic problems with the choice of study sites, controls, and estimates of periods of protection. Full recovery is likely to be dictated by periodic recruitment patterns, growth, and longevities of the fish. Longevities of the large predators in coral reefs are often in the range of 15 to 45 yr (Choat \& Robertson 2000, Newman et al. 2000, Kamukuru et al. 2005). The combined findings of these recovery studies suggest that closed areas need to be maintained for at least 2 decades before the fish fauna approaches the full size and biomass.

Our data did not, however, indicate that there was an equilibrium biomass for the coral reef fish fauna. 

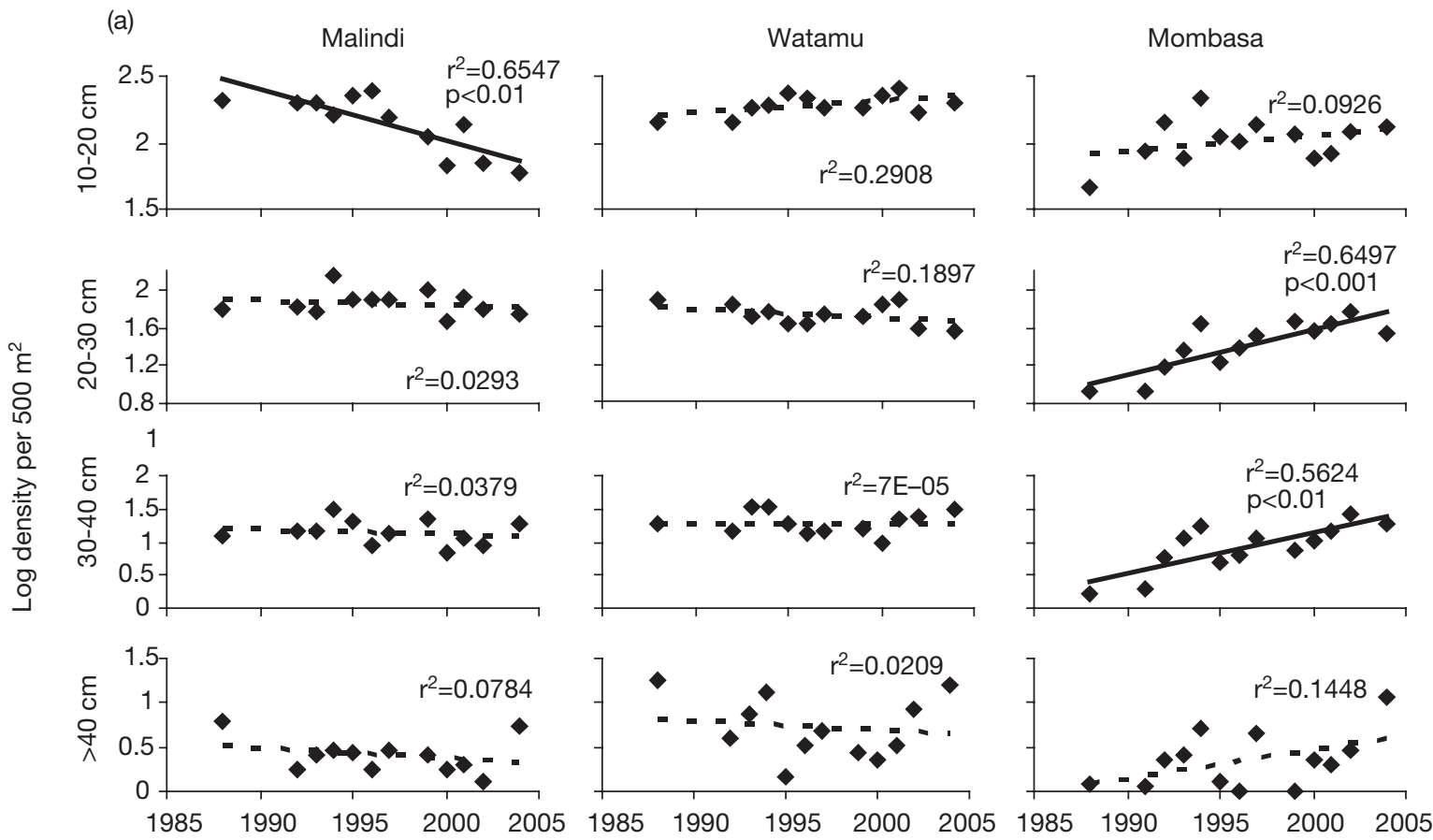

(b)
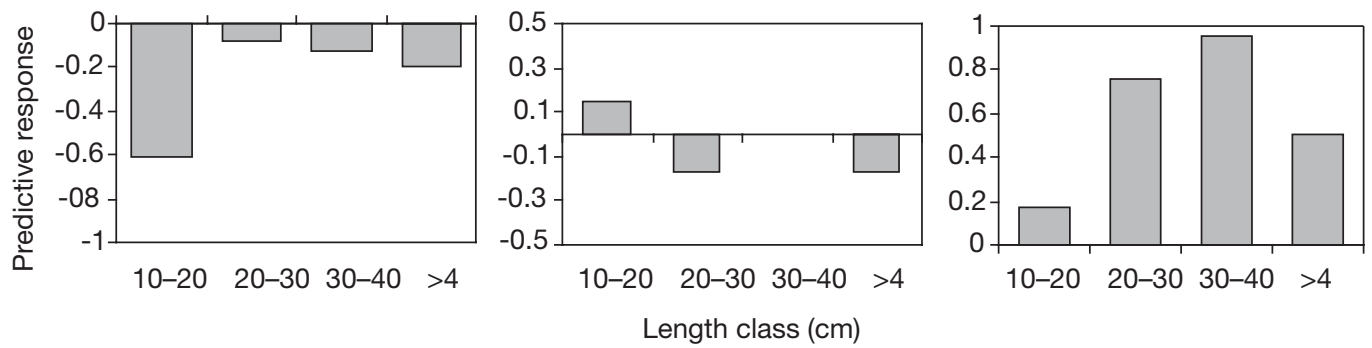

Fig. 3. (a) Scatter plot of the logarithmic density of the different size classes. Solid trend line indicates a significant regression. (b) Predicted responses to exploitation of $10 \mathrm{~cm}$ body size categories, calculated as the predicted difference in abundance (from regression line) between first and final surveys for fish in the 3 most frequently sampled Kenya marine protected areas

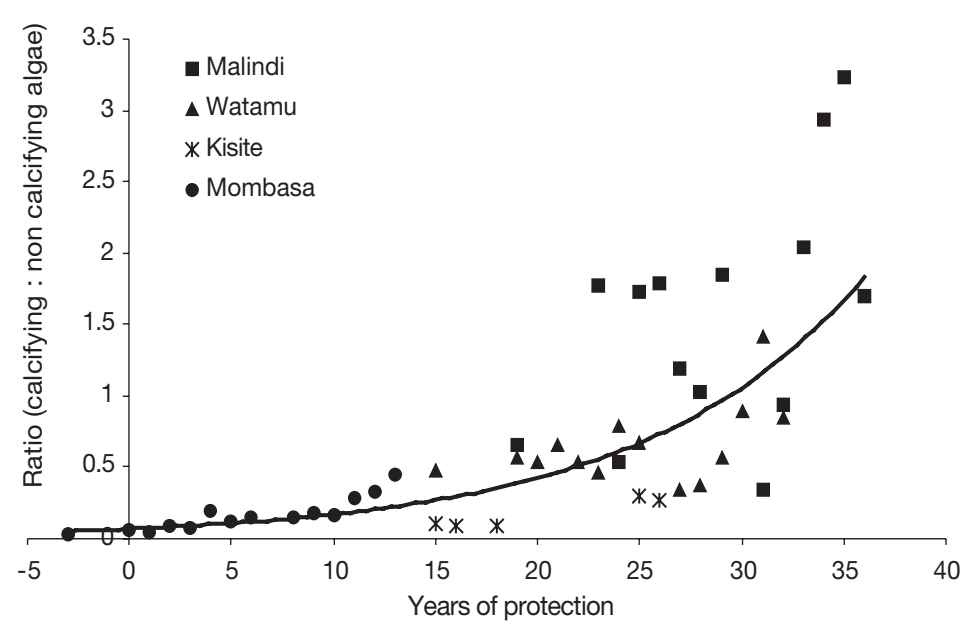

Fig. 4. Scatter plot of the ratio of calcifying (red and green coralline or calcareous algae) to non-calcifying (turf and frondose algae) algae as a function of the age of the protected area. Best-fit line shown for all sites combined; however statistics in 'Results' relate to individual sites
Although the maximum biomass was $1200 \mathrm{~kg}$ $\mathrm{ha}^{-1}$ at $\sim 20 \mathrm{yr}$, it would appear that beyond $20 \mathrm{yr}$ there was a small decline in biomass. The $1200 \mathrm{~kg}$ estimate is reasonable based on energy-based modeling studies (McClanahan 1992, 1995), but it is more surprising that there was a decline after 20 yr. This decline might simply be due to sitespecific patterns and an artifact of the low overlap between sites over time, but if not an artifact, it could be attributable to slow recovery processes, and explanations might include changes in benthic cover and net production (Fig. 4), density or biomass-dependent emigration of fish from older parks (Rodwell et al. 2003), and recovery of higher trophic levels and reduced biomass of their lower trophic level prey (Graham et al. 2003). We present changes in the ratio of calcifying to non-calcifying algae as a possible explanation because as this ratio increases it is expected to reduce net benthic production (Steneck \& Dethier 1994) and have sub- 
sequent effects on the animal biomass of the reefs (McClanahan 1992). Malindi, the site with the highest calcifying to non-calcifying ratio, was also the site with the largest declines in fish biomass. Despite this indirect evidence, we also recognize that this is only 1 possible explanation, and the presented pattern is correlative rather than causative, and the alternative suggestions mentioned above are among factors that may have contributed to this pattern. It does, however, suggest that other ecological processes in recovering coral reefs are also slow and on the scale of decades and possibly caused by the recovery of fish biomass. It is expected that grazing pressure will increase with increased recovery, and this is expected to improve conditions for calcifying algae (Steneck \& Dethier 1994). Although perhaps surprising for coral reefs, this may be analogous to reported declines in forest production and biomass in old forests due to reduced availability of soil phosphorus (Wardle et al. 2004).

Biomass estimates in the fished areas along the coast for the same habitat demonstrate no positive trends through time, and the mean value is below $150 \mathrm{~kg} \mathrm{ha}^{-1}$ in all areas sampled. The biomass of $150 \mathrm{~kg} \mathrm{ha}^{-1}$ is close to the biomass of Mombasa marine park prior to enforcement, and indicates that the observed trends are a result of protection from fishing, and not other environmental, biological, or fishing pressure factors. Although we acknowledge that there may be some variation in response to protection between the 4 MPAs, they are all controlled by the same management practice, have similar habitat and benthic cover, and are geographically in close proximity (Table 1).

The size spectra of fish may be a useful way to judge the intensity of and recovery from fishing (Dulvy et al. 2004, Graham et al. 2005) if some theoretical, such as the energetic equivalence rule (Damuth 1981), or frequently observed equilibrium spectra are found for coral reef fishes. Ackerman et al. (2004) found evidence for a close match between the theoretically expected slope of -0.75 for body size and abundance for the largest size classes of fish in their study at Orpheus Island, Australia, but poorer fit when including the smaller fishes with slopes ranging from -0.32 to -0.86 . Their one-time study indicates that the slope depends on the choice of the studied size classes used in the field or analyses, and our temporally replicated study suggests that even when size classes are fixed the slope does change over time, sometimes quite quickly. Based on studies of fishing pressure in Fiji, spectral slopes are expected to become steeper with increasing fishing pressure (Dulvy et al. 2004, Graham et al. 2005) and would therefore be expected to become less steep after relaxation of fishing pressure. We did find a weak positive rise in the slope in the youngest park over time, associated with increases in the 2 largest size classes, but it was also quite variable and did not converge on an expected equilibrium. The scatter in the older parks was large and not useful in identifying an equilibrium slope. High variation in spectral slope data from all studies combined suggests that there is little evidence for an equilibrium size spectral slope for coral reef fishes at this location and habitat. Consequently, it is more likely that other ecological factors are influencing coral reef fish sizes, and identifying the many other possible causes will require additional research.

In accordance with the results here, significant trends in abundance-biomass (height) were also found with changes in fishing pressure in Fiji (Dulvy et al. 2004, Graham et al. 2005). However, in contrast to the results in Fiji, where a gradient of fishing intensity was associated with indirect responses in the smallest size classes (Dulvy et al. 2004), only the Malindi data suggested a decline of smaller size classes with increasing time since fishing closure. Further use of size spectra analysis across gradients of fishing pressure or through time will improve understanding of the size-based implications of fishing and difference in management regimes on coral reefs. The concurrent trends in aggregated biomass in this study suggest reliable measurements of the effects of and recovery from fishing. Given that biological overfishing occurs when the stock falls below half of the pristine biomass (Clark 1985), the value $1200 \mathrm{~kg} \mathrm{ha}^{-1}$ (for fish $>10 \mathrm{~cm}$ ) provides a good basis for estimating the condition and providing targets for fish biomass on fished reefs in this region. It should be appreciated that this pristine biomass is expect to differ on reefs in different regions, with depths and benthic cover, and should be extrapolated to other reefs with caution. For example, the lowest or 'unfished' areas from the Fiji and Seychelles studies suggest fish biomass ranging between 500 and $1000 \mathrm{~kg} \mathrm{ha}^{-1}$ (Jennings et al. 1995, Jennings \& Polunin 1997, Dulvy et al. 2004), which may be due to regional, habitat, and productivity differences, or reefs that are lightly fished, or have not recovered from previous fishing.

Given that most coral reef closed areas are recent and not well managed (Kelleher et al. 1995), and that for the purposes of ecosystem management, there is a need to determine equilibrium states of reef fishes and ecosystems for comparison with exploited ecosystems, it behooves nations with coral reef fisheries to have multiple, fully closed areas that are permanently and properly enforced for many decades. The time for recovery is significantly long, and unless permanently closed areas are part of a fisheries-management program, there is little basis on which to judge the condition of reefs and fisheries with reefs undisturbed by fishing (Pauly et al. 1998). Light or restricted fishing, 
lax enforcement of closure, and rotational or periodic harvesting are all likely to set back the recovery of the ecosystems (Russ \& Alcala 1998, McClanahan \& Mangi 2000). Periodic harvesting may be a useful form of fisheries management but it should not replace (but, rather, be used together with) permanently closedarea management.

Acknowledgements. This work resulted from a long-term monitoring program cleared by the Kenyan Ministry of Science and Technology and with logistic support provided by Kenya Wildlife Services. The comments of J. Bythell, T. Daw, $\mathrm{S}$. Wilson and 2 reviewers helped improve the manuscript.

\section{LITERATURE CITED}

Ackerman JL, Bellwood DR, Brown JH (2004) The contribution of small individuals to density-body size relationships: examination of energetic equivalence in reef fishes. Oecologia 139:569-571

Allen CR, Holling CS (2002) Cross-scale structure and scale breaks in ecosystems and other complex system. Ecosystems 5:315-318

Bianchi G, Gislason H, Graham K, Hill L and 7 others (2000) Impact of fishing on size composition and diversity of demersal fish communities. ICES J Mar Sci 57:558-571

Browman HI, Stergiou KI (2004) Perspectives on ecosystembased approaches to the management of marine resources. Mar Ecol Prog Ser 274:269-303

Choat JH, Robertson DR (2002) Age-based studies. In: Sale PF (ed) Coral reef fishes: dynamics and diversity in a complex ecosystem. Academic Press, San Diego, CA, p 57-80

Clark CW (1985) Bioeconomic modelling and fisheries management. Wiley-Interscience, New York

Cote IM, Mosquera I, Reynolds JD (2001) Effects of marine reserve characteristics on the protection of fish populations: a meta-analysis. J Fish Biol 59:178-189

Daan N, Gislason H, Pope JG, Rice JR (2003) Changes in the North Sea fish community: evidence of indirect effects of fishing? ICES CM 10:1-11

Damuth J (1981) Population density and body size in mammals. Nature 290:699-700

Denny NH, Jennings S, Reynolds JD (2002) Life-history correlates of maximum population growth rates in marine fishes. Proc R Soc Lond B 269:2229-2237

Dulvy NK, Polunin NVC, Mill AC, Graham NAJ (2004) Size structural change in lightly exploited coral reef fish communities: evidence for weak ecological release. Can J Fish Aquat Sci 61:466-475

Graham NAJ, Evans RD, Russ GR (2003) The effects of marine reserve protection on the trophic relationships of reef fishes on the Great Barrier Reef. Environ Conserv 30: 200-208

Graham NAJ, Dulvy NK, Jennings S, Polunin NVC (2005) Size spectra as indicators of the effects of fishing on coral reef fish assemblages. Coral Reefs 24:118-124

Halpern B (2003) The impact of marine reserves: do reserves work and does reserve size matter? Ecol Appl 13:117-137

Halpern BS, Warner RR (2002) Marine reserves have rapid and lasting effects. Ecol Lett 5:361-366

Jennings S, Polunin NVC (1997) Impacts of predator depletion by fishing on the biomass and diversity of non-target reef fish communities. Coral Reefs 16:71-82
Jennings S, Grandcourt EM, Polunin NVC (1995) The effects of fishing on the diversity, biomass and trophic structure of Seychelles' reef fish communities. Coral Reefs 14:225-235

Jennings S, Reynolds JD, Polunin NVC (1999) Predicting the vulnerability of tropical reef fishes to exploitation with phylogenies and life histories. Conserv Biol 13:1466-1475

Kamukuru AT, Hecht T, Mgaya YD (2005) Effects of exploitation on age, growth and mortality of the blackspot snapper, Lutjanus fulviflamma, at Mafia Island, Tanzania. Fish Manag Ecol 12:45-55

Kelleher G, Bleakley C, Wells S (eds) (1995) A global representative system of marine protected areas, Vol 1. World Bank, Washington, DC

Kerr SR, Dickie LM (2001) The biomass spectrum: a predator-prey theory of aquatic production Columbia University Press, New York

Levin SA (2000) Multiple scales and the maintenance of biodiversity. Ecosystems 3:498-506

Link JS (2002) What does ecosystem-based fisheries management mean? Fisheries 27:18-21

McClanahan TR (1992) Resource utilization, competition and predation: a model and example from coral reef grazers. Ecol Model 61:195-215

McClanahan TR (1994) Kenyan coral reef lagoon fish: effects of fishing, substrate complexity, and sea urchins. Coral Reefs 13:231-241

McClanahan TR (1995) A coral reef ecosystem-fisheries model: impacts of fishing intensity and catch selection on reef structure and processes. Ecol Model 80:1-19

McClanahan TR (2000) Recovery of the coral reef keystone predator, Balistapus undulatus, in East African marine parks. Biol Conserv 94:191-198

McClanahan TR, Kaunda-Arara B (1996) Fishery recovery in a coral-reef marine park and its effect on the adjacent fishery. Conserv Biol 10:1187-1199

McClanahan TR, Mangi S (2000) Spillover of exploitable fishes from a marine park and its effect on the adjacent fishery. Ecol Appl 10:1792-1805

McClanahan TR, Shafir SH (1990) Causes and consequences of sea urchin abundance and diversity in Kenyan coral reef lagoons. Oecologia 83:362-370

McClanahan TR, Polunin NVC, Done T (2002) Ecological states and the resilience of coral reefs. Conserv Ecol 6:18

Mosquera I, Cote IM, Jennings S, Reynolds JD (2000) Conservation benefits of marine reserves for fish populations. Anim Conserv 4:321-332

Newman SJ, Cappo M, McB.Williams D (2000) Age, growth, mortality rates and corresponding yield estimates using otoliths of the tropical red snappers, Lutjanus erythropterus, L. malabaricus and L. sebae, from the central Great Barrier Reef. Fish Res 48:1-14

Pauly D, Christensen V, Dalsgaard J, Froese R, Torres Jr F (1998) Fishing down marine food webs. Science 279: 861-863

Pikitch EK, Santora C, Babcock EA, Bakun A and 13 others (2004) Ecosystem-based fishery management. Science 305:346-347

Rochet MJ, Trenkel VM (2003) Which community indicators can measure the impact of fishing? A review and proposals. Can J Fish Aquat Sci 60:86-99

Rodwell LD, Barbier EB, Roberts CM, McClanahan TR (2003) The importance of habitat quality for marine reserve-fishery linkages. Can J Fish Aquat Sci 60:171-181

Russ GR, Alcala AC (1998) Natural fishing experiments in marine reserves 1983-1993: roles of life history and fishing intensity in family responses. Coral Reefs 17:399-416

Russ GR, Alcala AC (2004) Marine reserves: long-term pro- 
tection is required for full recover of predatory fish populations. Oecologia 138:622-627

Sale PF, Cowen RK, Danilowicz BS, Jones GP and 7 others (2005) Critical science gaps impede use of no-take fishery reserves. Trends Ecol Evol 20:74-80

Sheppard C, Wells SM (eds) (1988) Coral reefs of the world, Vol 2. UNEP/IUCN, Gland

Steneck RS, Dethier MN (1994) A functional group approach to the structure of algal-dominated communities. Oikos 69:476-498

Trenkel VM, Rochet MJ (2003) Performance of indicators derived from abundance estimates for detecting the

Editorial responsibility: Otto Kinne (Editor-in-Chief), Oldendorf/Luhe, Germany impact of fishing on a fish community. Can J Fish Aquat Sci 60:67-85

Wardle DA, Walker LR, Bardgett RD (2004) Ecosystem properties and forest decline in contrasting long-term chronosequences. Science 305:509-513

Watson M, Ormond RFG (1994) Effect of an artisanal fishery on the fish and urchin populations of a Kenyan coral reef. Mar Ecol Prog Ser 109:115-129

Willis TJ, Millar RB, Babcock RC, Tolimieri N (2003) Burdens of evidence and the benefits of marine reserves: putting Descartes before des horse? Environ Conserv 30: 97-103

Submitted: August 31, 2004; Accepted: February 10, 2005

Proofs received from author(s): May 25, 2005 